Research Article

\title{
Effect of communication with electronic social media networking in emergency department of a rural tertiary care centre
}

\author{
Anil Kumar, Somendra Pal Singh*, Prashant Gupta, Umesh Gupta, Mohit Gupta, \\ Praveen Singh, Manas Prakash
}

Department of Surgery, UP Rural Institute of Medical Sciences and Research, Saifai, Etawah, UP, India

Received: 23 February 2016

Accepted: 05 March 2016

\section{*Correspondence:}

Dr. Somendra Pal Singh,

E-mail: somendrachauhan@hotmail.com

Copyright: () the author(s), publisher and licensee Medip Academy. This is an open-access article distributed under the terms of the Creative Commons Attribution Non-Commercial License, which permits unrestricted non-commercial use, distribution, and reproduction in any medium, provided the original work is properly cited.

\section{ABSTRACT}

Background: Mode of communication in emergency is of prime importance when it comes to patient management or reporting of the patient. An expert opinion and timely information to senior consultants is to be always soughed whenever in doubt. A common electronic media platform can be very beneficial in such circumstances.

Methods: All the residents and consultants of emergency team were connected on a common platform using WhatsApp and upload of information was done by residents on duty which was cleared by consultants.

Results: A decrease in response time about diagnosis or management of patient was observed to be decreased along with more clear and visual information was available to seniors for their advice. A common platform for reporting and consultation was more appreciated among surgeons and Orthopedician.

Conclusions: Using a common electronic platform for communication may be felt cumbersome with some amount of extra burden but definitely results into more accurate delivery of care to patients with in time expert opinion.

Keywords: WhatsApp, Emergency, Residents, Response time

\section{INTRODUCTION}

Till now the most commonly used mode of communication among any emergency team in a hospital setup is verbal via telephone or through ward boys by call register. But it have a lots of limitations being network problem, busy on another call, fear of calling again and again, not having contact number, fear of calling consultants at late night, and no visual representation of the situation. Recently to add to verbal information photographs taken by digital cameras and transfer by using email had gained a lot of popularity as a form of telemedicine. ${ }^{1}$ Working in emergency is never a single man show perhaps it's all about early receiving of the patient, early communication with the seniors and coordination with quick action for the management of patient as per advice of the team. WhatsApp is an early stage technology startup founded to build a better short message service alternative. It is a proprietary cross platform instant messaging application for smart phones. Santa Clara, California based company WhatsApp Inc. that was founded in 2009 by Brian Acton and Jan Koum developed it. ${ }^{2}$ In this study, we observed the effect of bringing the whole Emergency team on a common messenger platform using WhatsApp. In addition, we analyzed the influence of this method on the reporting and response time for management of patients in Emergency Department.

\section{METHODS}

This study was conducted at emergency department of UP Rural Institute of Medical Sciences and Research from July 2015 to December 2015 i.e. 6 months duration, and all the residents, assistant consultants and associate consultants regardless of Department was connected 
using a common WhatsApp platform with group name "RIMS Emergency" with in charge of emergency as group moderator. All the rotating emergency teams were added and was notified day prior of their emergency. A common specific notification alert tone was set among for all the members in the group. On joining the group, the residents were instructed to endorse all the patients of the team, new consults, admissions, discharges, OR cases, plans, uploading of pre-operative, intra-operative and post-operative photographs for documentation. Whenever any resident of the group see a patient in which he requires a senior consultation or reference from any other department he uploads information of the patient with the team members using this application. In addition to word chat, images and video clip shots taken by smart phone were also attached with the conversation. The information from junior residents was responded by respective consultants immediately. In case of no response the consultant was contacted on phone immediately. If an opinion from consultant of other department was needed the contact was made on the phone but cross references among residents was allowed in the group.

Efficacy of communication and response of residents on this common platform was recorded at the end of 6 months.

\section{RESULTS}

A total of 14 surgery residents, 8 medicine residents, and 8 orthopedics residents and 25 consultants from all 3 departments were joined in the group by emergency in charge over this period.
A total of 2171 times information was uploaded by residents on duty for consultation and the time taken by a senior member to respond was noted. A decrease in response time was observed along with time taken in final decision of patient management which unfortunately cannot be compared as previous data on same parameter was not available in our emergency department.

Table 1: The time lapse between initial reporting by resident and first response from senior.

\begin{tabular}{|ll|}
\hline $\begin{array}{l}\text { Time taken for } \mathbf{1}^{\text {st }} \\
\text { response }\end{array}$ & Number of communication \\
\hline$<1 \mathrm{~min}$ & $424(19.5 \%)$ \\
\hline $1-5 \mathrm{~min}$ & $771(35.5 \%)$ \\
\hline $5-15 \mathrm{~min}$ & $656(30.2 \%)$ \\
\hline $15-30 \mathrm{~min}$ & $320(14.7 \%)$ \\
\hline
\end{tabular}

Telephonic call was made after 30 minutes if no response was received.

At the completion of the rotation, all the 30 rotating residents and 25 consultants were asked about their opinion regarding use of this application as a mode of communication.

At the end of the study 29 out of 30 residents and 24 out of 25 consultants was of opinion that using a common electronic media platform is a better method of communication in emergency department. Such common platform was more popular and appreciated among residents and consultants of surgery and medicine.

Table 2: Opinion of residents and consultants about common communication platform.

\begin{tabular}{|c|c|c|c|c|c|c|}
\hline $\begin{array}{l}\text { Opinion regarding their experience of using WhatsApp in emergency as a } \\
\text { common platform for communication }\end{array}$ & \multicolumn{3}{|c|}{ Residents } & \multicolumn{2}{|c|}{ Consultants } & \\
\hline Poor method, not better than conventional telephonic method & 0 & +0 & +1 & 0 & +0 & +1 \\
\hline Better than telephonic method, but undue burden of notifications & 3 & +1 & +3 & 2 & +1 & +3 \\
\hline Good method, but should be department specific & 3 & +2 & +3 & 4 & +4 & +1 \\
\hline Very impressive method must be included for wards too & 2 & +2 & +1 & 3 & +3 & +0 \\
\hline Excellent method and other departments should also be connected & 6 & +3 & +0 & 1 & +2 & +0 \\
\hline
\end{tabular}

\section{DISCUSSION}

Identification of first signs of complications and preparedness for the management and its quick application is what decides the patient's outcome. This method of communication reduced the time interval between the first recognition of any untoward effect and starting the management. The time lapse between writing a reference for consultation of other department and patient being attended by the on duty resident decreased. The redundant steps of vertical reporting system were eliminated by real time WhatsApp chat. There was input from all residents even not on duty and registrars based on high quality information including photographs, videos and chats. Also any peculiar information relating to previous emergency duty was shared quickly. The verbal presentation of any event was felt out-dated in comparison to detailed real time chat system with multiple opinions and information received simultaneously. It finally resulted in early diagnosis, easy cross referencing, and informed seniors about each and every minor details of emergency.

The disadvantage of this communication system was round the clock login by members, inability to use conversations as medicolegal records, complicated chats 
when multiple patients are being discussed, and burden of notification of patients of other streams as they discuss their respective consultants. This method had been used for free flap monitoring communication and had been found very effective tool in past. $^{3}$

Hsiehet al has used Tele consultation in plastic surgery using images from inbuilt camera of cellphones. ${ }^{4}$

Johnson et al in a similar study on analysis of communication among surgical teams in emergency found that use of Watsapp decreased the response time among residents and interns and helped to flatten the hierarchy. ${ }^{5}$

Choudhari ${ }^{6}$ in a study found incidences regarding patient management which were handled, in a timely fashion by using this application. In addition opinion of residents in the unit was sought regarding the effectiveness of this method of communication. Overall majority of residents were satisfied with this mode of communication.

Robert $\mathrm{Wu}$ et al in a study found that there was a perceived improvement in efficiency over the use of pagers for clinical communication for physicians, nurses, and allied health professionals. ${ }^{7}$ In particular, residents found that the use of smartphones helped to increase their mobility and multitasking abilities. Unprofessional behaviours were observed in the use of smartphones by residents.

This method of communication sometimes resulted in over exhaustiveness and discussions over minor issues but still the goal of emergency team was achieved now with more enthusiasm and management of patients improved a lot. The data of this study cannot be compared as no data available about the initiation of management and response of consultants available before this common platform. This platform also improved the management as advice from consultants on leave or at a distance was available readily.

In future, this platform can be used to connect all Departments of the hospital including ophthalmology, ENT, anaesthesia and obstetrics \& gynaecology.

\section{CONCLUSION}

A common messenger platform like WhatsApp provides quick and expert health care along with proper supervision of consultants even at odd timings resulting into fast and appropriate management of the patients. More platform specific to the needs of doctors must be developed for easy and fast communication with department specific subgroups to minimize extra notification trafficking.

Funding: No funding sources

Conflict of interest: None declared

Ethical approval: The study was approved by the institutional ethics committee

\section{REFERENCES}

1. Baldwin AJ, Langton SG. Postoperative monitoring of flaps by digital camera and internet link. Br J Oral Maxillofac Surg. 2001;39:120-1.

2. Wikipedia, the free encyclopedia en. [Last updated on 2013 Mar 21]. Available from: http://www.Wikipedia.org/wiki/Whats App. Accessed on 01 February,2016.

3. Knobloch K, Gohritz A, Vogt PM. Cell phone-based multimedia messaging service in reconstructive microsurgery: A novel telemedicine application. Plast Reconstr Surg. 2009;123:220e-2.

4. Hsieh CH, Tsai HH, Yin JW, Chen CY, Yang JC, Jeng SF. Tele consultation with the mobile cameraphone in digital soft-tissue injury: A feasibility study. Plast Reconstr Surg. 2004;114:1776-82.

5. Johnson. Smartphones let surgeons know WhatsApp: an analysis of communication in emergency surgical teams. Am J Surg. 2015;209(1):45-51.

6. Choudhari. Study on effectiveness of communication amongst members at department of orthopedics surgery unit 3 using smartphone and mobile WhatsApp. Int Surg J. 2014;1(1):9-12.

7. Robert $\mathrm{Wu}$. An evaluation of the use of smartphones to communicate between clinicians: a mixedmethods study. J Med Internet Res. 2011;13(3):e59.

Cite this article as: Kumar A, Singh SP, Gupta P, Gupta U, Gupta M, Singh P, Prakash M. Effect of communication with electronic social media networking in emergency department of a rural tertiary care centre. Int Surg J 2016;3:855-7. 